\title{
MULTIPLE SHIFTS AND FRACTIONAL INTEGRATION \\ IN THE US AND UK UNEMPLOYMENT RATES
}

\author{
Guglielmo Maria Caporale \\ Brunel University, London
}

\author{
Luis A. Gil-Alana \\ University of Navarra
}

May 2008

\begin{abstract}
This paper analyses the long-run behaviour of the US and UK unemployment rates by testing for possibly fractional orders of integration and multiple shifts using a sample of over 100 annual observations. The results show that the orders of integration are higher than 0 in both series, which implies long memory. If we assume that the underlying disturbances are white noise, the values are higher than 0.5, i.e., nonstationary. However, if the disturbances are autocorrelated, the orders of integration are in the interval $(0,0.5)$, implying stationarity and mean-reverting behaviour. Moreover, when multiple shifts are taken into account, unemployment is more persistent in the US than in the UK, implying the need for stronger policy action in the former to bring unemployment back to its original level.
\end{abstract}

Keywords: C22, E32

JEL Classification: Unemployment; Persistence; Long memory; Multiple shifts.

Corresponding author: Professor Guglielmo Maria Caporale, Centre for Empirical Finance, Brunel University, Uxbridge, Middlesex UB8 3PH, UK. Tel.: +44 (0)1895 266713. Fax: +44 (0)1895 269770. Email: Guglielmo-Maria.Caporale@brunel.ac.uk

Acknowledgments: The second-named author gratefully acknowledges financial support from the Ministerio de Educación y Ciencia through the SEJ2005-07657/ECON project. We are also grateful to Natalie Hegwood for kindly providing the data. Comments of an anonymous referee are also gratefully acknowledged. 


\section{Introduction}

The stationary or nonstationary nature of the unemployment rate has been the study of numerous papers in recent years. On the one hand, the hysteresis approach to unemployment suggests that unemployment is a nonstationary highly persistent variable, since fluctuations in the natural rate of unemployment (the NAIRU) are permanent. The standard econometric approach for modelling this type of behaviour relies on a unit root specification. On the other hand, the rejection of the unit root hypothesis supports reversion to a natural rate. The slow reversion often found is normally referred to as hysteresis. Blanchard and Summers (1986, 1987) define it as: "a case where the degree of dependence is very high, where the sum of coefficients is close but not necessarily equal to one". This high persistence of shocks is a feature, among others, of "insider" models (see Lindbeck and Snower, 1988), or of models in which fixed and sunk costs make current unemployment a function of past labour demand (see Cross, 1994, 1995). In "structuralist" models (see Phelps, 1994) the natural rate is "endogenised": as in NAIRU models, unemployment is viewed as having an equilibrium level to which it generally reverts when hit by shocks, but it is also thought to be subject to infrequent structural breaks, resulting from changes in economic fundamentals, which affect the equilibrium itself. Hence the unemployment series should be stationary (or, more generally, mean-reverting) provided one allows for breaks.

The standard approach which uses classical unit root tests (e.g. Dickey and Fuller, ADF, 1979; Phillips and Perron, PP, 1988; Kwiatkowski et al., KPSS, 1992; or some of their recent developments, i.e., Elliot et al., 1996; $\mathrm{Ng}$ and Perron, 2001, etc.) for testing the above theories of unemployment has two important limitations. First, it only considers integer values for the orders of integration ( 1 in the case of unit roots, and 0 for stationarity), but it does not allow for fractional alternatives, where the fractional parameter $\mathrm{d}$ can take any 
value in the interval $[0,1]$ or even above 1 . Besides, these methods do not allow the rate to which reversion occurs (the natural rate) to shift, and are therefore inadequate to describe the pattern observed in unemployment rates. Note that under hysteresis (or persistence - see, e.g., Blanchard and Summers, 1986, 1987 and Cross, 1987) the order of integration (denoted by d) should be equal to or at least close to 1 , implying that the effects of the shocks are permanent (if $\mathrm{d}=1$ ) or at least highly persistent (if $\mathrm{d}<1$ though close to 1 ), whilst infrequent breaks would give support to the structuralist view (Phelps, 1994). On the other hand, a value of d close to 0 would favour NAIRU theories (see, e.g., Friedman, 1968).

In this paper, we deal with the two above-mentioned problems (i.e., not considering fractional alternatives and/or mean shifts) by means of a procedure that enables us to consider both fractional orders of integration and multiple mean shifts. By using fractional orders of integration, we allow for a much richer degree of flexibility in the dynamic behaviour of the series. Thus, if the order of integration (denoted by d) is higher than 0 but smaller than 0.5 , the series still will be covariance stationary, though the effects of shocks will take longer to disappear than in the case of $d=0$. In the latter case, the series is said to be "short memory" and the effects will disappear fairly soon, according to an exponential decay, if, for example, the observations are autoregressive. On the other hand, if $d>0$, the series is said to be "long memory" and the decay is hyperbolic. Also, if d belongs to the interval $[0.5,1]$, the series is no longer covariance stationary but is still mean reverting, with shocks disappearing in the very long run. Further, it is well known that standard procedures for nonstationary unit roots (ADF, PP, KPSS, etc.) have extremely low power if the alternatives are of a fractional form (Diebold and Rudebusch, 1991; Hassler and Wolters, 1994; Lee and Schmidt, 1996, etc.). 
The existence of different regime shifts in time series has been found in recent years to be crucial in the determination of the long-memory parameter (see, e.g., Diebold and Inoue, 2001, Gourieroux and Jasiak, 2001; Granger and Hyung, 2004; etc.), as overlooking breaks may lead to spurious findings of long memory. For instance, Lobato and Savin (1998) argue that structural breaks may be responsible for the long memory in return volatility processes, and Engle and Smith (1999) investigated the relationship between structural breaks and long memory using a simple model where the data generating process consists of a mean process and a stationary error. Other authors such as Diebold and Inoue (2001) and Granger and Hyung (2004) argue consider that structural breaks and long memory are highly related and that it is difficult to distinguish one from another.

The testing procedure described in Section 2 enables us to consider unit and fractional orders of integration and has standard null and local limit distributions. This is a distinguishing feature of the tests compared with other methods for testing, such as unit root tests, where the limit distribution is non-standard, in the sense that critical values have to be calculated numerically in a case by case simulation study. Moreover, this standard limit distribution holds regardless of the inclusion or non-inclusion of deterministic components and thus is not affected by the inclusion of multiple mean shifts, as will be the case in the present study.

We focus on the US and the UK in particular since several studies (e.g., Alogoskoufis and Manning, 1988) have found that US unemployment typically displays lower persistence than in European countries such as the UK. The latter is a particularly interesting case because of the mixed evidence on whether persistence has decreased or increased there since the early 1980s when labour market reforms (aimed at eliminating rigidities) were implemented by the Conservative government led at the time by Mrs. 
Thatcher. Contrary to what one would expect, some authors, such as Blanchflower and Freeman (1994), have reported a slower transition from unemployment to employment in the Thatcher years.

The outline of the paper is as follows: In Section 2 we briefly describe the procedure employed here. Section 3 applies this method to examine the orders of integration of the UK and US unemployment rates allowing for multiple shifts. Section 4 contains some concluding comments.

\section{The testing procedure}

We assume that $\mathrm{y}_{\mathrm{t}}$ is the time series we observe, and consider the model:

$$
y_{t}=\sum_{i=1}^{k} \beta_{i} z_{i t}+x_{t}, \quad t=1,2, \ldots
$$

where $z_{i t}=1 \mathrm{I}\left(\mathrm{t} \in \mathrm{T}_{\mathrm{i}}\right)$ and $\mathrm{T}_{\mathrm{i}}$ is a subsample of the time period examined, so that $\mathrm{z}_{\mathrm{it}}$ represents a mean shift in the time interval $T_{i}$. Also, we assume that $x_{t}$ in (1) is given by:

$$
(1-L)^{d} \quad x_{t}=u_{t}, \quad t=1,2, \ldots
$$

where $d$ can be any real number, $L$ is the lag operator $\left(\operatorname{Lx}_{t}=x_{t-1}\right)$ and $u_{t}$ is an $I(0)$ process, defined, for the purposes of the present study, as a covariance stationary process with spectral density function that is positive and finite at the zero frequency.

Note that the polynomial on the left-hand-side in (2) can be expressed in terms of its Binomial expansion,

$$
(1-L)^{d}=\sum_{j=0}^{\infty}\left(\begin{array}{l}
d \\
j
\end{array}\right)(-1)^{j} L^{j}=1-d L+\frac{d(d-1)}{2} L^{2}-\ldots,
$$

such that, for all real d, 


$$
(1-L)^{d} x_{t}=x_{t}-d x_{t-1}+\frac{d(d-1)}{2} x_{t-2}-\ldots .
$$

Robinson (1994) proposed a Lagrange Multiplier (LM) test of the null hypothesis:

$$
H_{o}: d=d_{o}
$$

in a model given by (1) and (2) for any given real value $d_{0}$. Specifically, the test statistic takes the form:

$$
\hat{R}=\hat{r}^{2} ; \quad \hat{r}=\left(\frac{T}{\hat{A}}\right)^{1 / 2} \frac{\hat{a}}{\hat{\sigma}^{2}}
$$

where $\mathrm{T}$ is the sample size and

$$
\begin{gathered}
\hat{a}=\frac{-2 \pi}{T} \sum_{j=1}^{T-1} \psi\left(\lambda_{j}\right) g\left(\lambda_{j} ; \hat{\tau}\right)^{-1} I\left(\lambda_{j}\right) ; \quad \hat{\sigma}^{2}=\sigma^{2}(\hat{\tau})=\frac{2 \pi}{T} \sum_{j=1}^{T-1} g\left(\lambda_{j} ; \hat{\tau}\right)^{-1} I\left(\lambda_{j}\right) ; \\
\hat{A}=\frac{2}{T}\left(\sum_{j=1}^{T-1} \psi\left(\lambda_{j}\right)^{2}-\sum_{j=1}^{T-1} \psi\left(\lambda_{j}\right) \hat{\varepsilon}\left(\lambda_{j}\right)^{\prime} \times\left(\sum_{j=1}^{T-1} \hat{\varepsilon}\left(\lambda_{j}\right) \hat{\varepsilon}\left(\lambda_{j}\right)^{\prime}\right)^{-1} \times \sum_{j=1}^{T-1} \hat{\varepsilon}\left(\lambda_{j}\right) \psi\left(\lambda_{j}\right)\right) \\
\psi\left(\lambda_{j}\right)=\log \left|2 \sin \frac{\lambda_{j}}{2}\right| ; \quad \hat{\varepsilon}\left(\lambda_{j}\right)=\frac{\partial}{\partial \tau} \log g\left(\lambda_{j} ; \hat{\tau}\right) ; \quad \lambda_{j}=\frac{2 \pi j}{T} .
\end{gathered}
$$

The function $g$ above is a known function coming from the spectral density function of $\mathrm{u}_{\mathrm{t}}$,

$$
f\left(\lambda ; \sigma^{2} ; \tau\right)=\frac{\sigma^{2}}{2 \pi} g(\lambda ; \tau), \quad-\pi<\lambda \leq \pi,
$$

$\hat{\tau}=\arg \min _{\tau \in T^{*}} \sigma^{2}(\tau)$, where $\mathrm{T}^{*}$ is a suitable compact subset of the $\mathrm{R}^{\mathrm{q}}$ Euclidean space, and $\mathrm{I}\left(\lambda_{\mathrm{j}}\right)$ is the periodogram of $\hat{u}_{t}$, where

$$
\begin{gathered}
\hat{\mathrm{u}}_{\mathrm{t}}=(1-\mathrm{L})^{\mathrm{d}_{\mathrm{o}}} \mathrm{y}_{\mathrm{t}}-\hat{\beta}^{\prime} \mathrm{w}_{\mathrm{t}}, \\
w_{t}=(1-L)^{d_{O}} z_{t} ; \quad \hat{\beta}=\left(\sum_{t=1}^{T} w_{t} w_{t}{ }^{\prime}\right)^{-1} \sum_{t=1}^{T} w_{t}(1-L)^{d_{O}} y_{t},
\end{gathered}
$$


with $\mathrm{z}_{\mathrm{t}}=\left(\mathrm{z}_{1 \mathrm{t}}, \ldots, \mathrm{z}_{\mathrm{kt}}\right)^{\mathrm{T}}$ and $\beta=\left(\beta_{1}, \ldots, \beta_{\mathrm{k}}\right)^{\mathrm{T}}$. Based on $\mathrm{H}_{\mathrm{o}}$ (3), Robinson (1994) established that under certain regularity conditions, ${ }^{1}$

$$
\hat{R} \rightarrow_{d} \quad \chi_{1}^{2}, \quad \text { as } \quad T \rightarrow \infty
$$

Thus, we are in a classical large-sample testing situation and the conditions on $u_{t}$ in (2) are far more general than Gaussianity, with a moment condition of only order 2 required. Because $\hat{R}$ involves a ratio of quadratic forms, its exact null distribution can be calculated under Gaussianity via Imhof's algorithm. However, a simple test is approximately valid under much wider distributional assumptions. Thus, an approximate one-sided test of $\mathrm{H}_{\mathrm{o}}(3)$

against the alternative $\mathrm{H}_{\mathrm{a}}: \mathrm{d}>\mathrm{d}_{\mathrm{o}}\left(\mathrm{d}<\mathrm{d}_{\mathrm{o}}\right)$ will reject $\mathrm{H}_{\mathrm{o}}(3)$ if $\hat{r}\left(=\sqrt{\hat{R}^{2}}\right)>\mathrm{z}_{\alpha}\left(\hat{r}<-\mathrm{z}_{\alpha}\right)$, where the probability that a standard normal variate exceeds $z_{\alpha}$ is $\alpha$. Robinson (1994) also showed that the test is efficient in the Pitman sense, i.e., that against local departures of form: $\mathrm{H}_{\mathrm{a}}: \mathrm{d}=\mathrm{d}_{\mathrm{o}}+\delta \mathrm{T}^{-1 / 2}$, with $\delta \neq 0, \hat{r}$ has a normal limit distribution with variance 1 and mean that cannot be exceeded (when $u_{t}$ is Gaussian) in absolute value by any rival regular statistic. This version of the Robinson's (1994) tests was used in empirical applications in Gil-Alana and Robinson (1997) and Gil-Alana (2000), and other versions of his tests based on seasonal (quarterly and monthly) and cyclical data can be found respectively in Gil-Alana and Robinson (2001) and Gil-Alana (1999, 2001).

\section{The US and UK unemployment rates}

The data used in this application are annual US unemployment rates from 1890 to 2001 and annual UK unemployment rates from 1885 to 2000. A complete discussion of the data can be found in Bianchi and Zoega (1996). Their data set ended in 1994 and has been updated

1 These conditions are very mild, regarding technical assumptions to be satisfied by the model in (1) and (2). 
using IMF's International Financial Statistics (IFS) data until 2000 for the UK and 2001 for the US (the two series are clearly stable in subsequent years).

\section{(Insert Figure 1 about here)}

Plots of the two time series are displayed in Figure 1. To determine the number of shifts in their behaviour, we use the results of Hegwood (2004), who adopts the Bai and Perron's (1998) procedures to determine the number of breaks. These authors showed that, for stationary non-trending data, their methods provide consistent estimates of the true break dates. ${ }^{2}$ Using a GAUSS program (provided by Perron), Hegwood (2004) concludes that the UK unemployment series contains three breaks: a positive shift in 1918; a negative shift in 1939, and a positive one in 1977. With respect to the US, she finds four shifts: negative in 1905; positive in 1926; negative in 1942, and positive in 1973 (see again Figure 1).

Having taken these to be the mean shifts in the two series, we next perform the version of Robinson's (1994) tests described in Section 2. We test $H_{o}(3)$ in (1) and (2) with $\mathrm{k}=3$ for the UK, and $\mathrm{k}=4$ for the US, for values $\mathrm{d}_{\mathrm{o}}=-1,-0.99,-0.98, \ldots, 0,0.01,0.02, \ldots$,

$1.98,1,99,2{ }^{3}$ assuming first that $\mathrm{u}_{\mathrm{t}}$ in (2) is white noise and then also allowing for autocorrelated disturbances - in particular, we consider $\mathrm{AR}(1)$ and $\mathrm{AR}(2)$ processes.

\section{(Insert Table 1 about here)}

Table 1 displays, for each country, the $95 \%$ confidence intervals of the values of $d_{o}$ for which $H_{0}$ (3) cannot be rejected, along with the value of $d_{o}$ which produces the lowest 
statistic in absolute value across d. These intervals were constructed as follows: We recomputed the tests sequentially for $d_{0}$-values $=-1,(0.01), 2$, choosing the values of $d_{o}$ for which $\mathrm{H}_{\mathrm{o}}$ cannot be rejected at the 5\% significance level. Thus, the value corresponding to the lowest statistic in absolute value (which is reported in the table in square brackets) will be an approximation to the maximum likelihood estimator. ${ }^{4}$ One can see that in all cases the values are higher for the US than for the UK, implying a higher degree of association between the observations in the former country. Also, these values substantially change depending on the modelling of the $\mathrm{I}(0)$ disturbances. Thus, if $\mathrm{u}_{\mathrm{t}}$ is white noise, the interval of the non-rejection values is $[0.67,1.19]$ for the UK, and slightly higher, $[0.79,1.30]$ for the US, and the unit root null hypothesis (i.e. $\mathrm{d}=1$ ) cannot be rejected in either of the two countries. Thus, according to this simple specification, the two series display hysteresis in their behaviour. However, a very different picture emerges if the disturbances are autocorrelated. In this case all the non-rejection values of $d$ are smaller than 0.5 , implying covariance stationarity and mean reversion. The values are again smaller for the UK than the US: for the former they range between 0 and 0.24 , whilst for the US they lie between 0.02 and 0.33 .

\section{(Insert Table 2 about here)}

Table 2 displays, for each series and each type of disturbances, the values of $d$ with the lowest $|\hat{\mathrm{r}}|$, the values of the test statistic, and estimates of the mean shifts and AR

\footnotetext{
2 Vogelsang (1997) develops similar methods for a single break, which allow for trending and nonstationary data.

${ }^{3}$ Thus, we allow for non-persistent $(\mathrm{d}<0)$ behaviour (Mandelbrot, 1977).
} 
parameters. The estimated orders of integration are, for the UK, 0.92, 0.09 and 0.11 , respectively for the cases of white noise, $\operatorname{AR}(1)$ and $\operatorname{AR}(2) \mathrm{u}_{\mathrm{t}}$. For the US the corresponding values are 1.02 (white noise) and 0.18 for $\mathrm{AR}(1)$ and $\mathrm{AR}(2)$ disturbances in turn. Moving on to the coefficients of the mean shifts, the cases when the values were significant at the $5 \%$ level are reported in bold in Table 2. One can see that all of them are statistically significant, except the first $\left(\beta_{1}\right)$ for the UK with autocorrelated disturbances. The last column of Table 2 reports some diagnostic tests carried out on the estimated residuals from each of the selected models. In particular, we perform tests of no serial correlation, homoscedasticity and functional form. Starting with the UK, we see that the only model to pass all the diagnostic tests is the one corresponding to the $\operatorname{AR}(1)$ case, which is,

$$
y_{t}=-0.272 z_{1 t}+3.887 z_{2 t}-3.198 z_{3 t}+2.393 z_{4 t}+x_{t} ;(1-L)^{0.09} x_{t}=u_{t} ; \quad u_{t}=0.628 u_{t-1}+\varepsilon_{t} .
$$

\section{(Insert Table 3 and Figure 2)}

For the US, the corresponding model is:

$$
\mathrm{y}_{\mathrm{t}}=3.632 \mathrm{z}_{1 \mathrm{t}}+0.027 \mathrm{z}_{2 \mathrm{t}}+6.601 \mathrm{z}_{3 \mathrm{t}}-2.945 \mathrm{z}_{4 \mathrm{t}}-3.735 \mathrm{z}_{5 \mathrm{t}}+\mathrm{x}_{\mathrm{t}} ;(1-\mathrm{L})^{0.18} \mathrm{x}_{\mathrm{t}}=\mathrm{u}_{\mathrm{t}} ; \mathrm{u}_{\mathrm{t}}=0.789 \mathrm{u}_{\mathrm{t}-1}-0.199 \mathrm{u}_{\mathrm{t}-2}+\varepsilon_{\mathrm{t}}
$$

Moreover, we performed Beran's (1992) goodness-of-fit statistic on the selected model for each country, and evidence in favour of the two models was found. In view of this, we can conclude that both series are stationary, though with a component of long-memory behaviour. Table 3 displays, for each country, the first ten (and the $20^{\text {th }}, 30^{\text {th }}, 40^{\text {th }}$ and $50^{\text {th }}$ ) impulse responses of the selected models, along with the responses corresponding to the

\footnotetext{
${ }^{4}$ Note that Robinson's (1994) method is based on the Whittle function, which is an approximation to the likelihood function.
} 
case of white noise $u_{t}$. As expected, these responses are extremely low for the latter case, and do not, in fact, decay for the US, where d is slightly higher than 1 . However, using the selected models, the decay is faster, combining the hyperbolic and the exponential decay from the fractional and AR structures respectively. Even 10 periods after the initial shock, the value of the impulse response is still $4.9 \%$ in the case of the UK. For the US, the effect is even higher, the value of the impulse response being $12.6 \%$ after 10 periods. The lower degree of decay in the US can also be noted in Figure 2, which shows the first 50 responses in both countries. The values are higher in all cases for the US. The results for the UK might appear surprising, as it is generally thought that there have been more rigidities in the UK labour market compared to the US one, and therefore a higher degree of persistence (and thus hysteresis) should be expected in the UK (se, e.g., Alogoskoufis and Manning, 1988, or Anderton, 1998). What our analysis reveals is that in fact, once multiple shifts are taken into account, the evidence supporting hysteresis vanishes. This might suggest that labour market reforms aimed at eliminating imperfections and rigidities preventing or slowing down labour market adjustment and clearing might have been more successful than previously thought in the UK. By contrast, the results for the US are in line with earlier findings supporting lower persistence (see again Alogoskoufis and Manning, 1988) and possibly a NAIRU model.

\section{Conclusions}

In this paper we have examined the stochastic behaviour of UK and US unemployment rates using a method that enables us to test unit and fractional orders of integration in the presence of multiple shifts. For this purpose we have employed Robinson's (1994) parametric procedure. Using this method, we can include deterministic trends in the model with no effect on its standard limit distribution. A limitation of this procedure is that one has to 
determine a priori the time and type of break. We do this by using Bai and Perron's (1988) method to determine the number of breaks. It is shown in Hegwood (2004) that UK unemployment contains three breaks: positive in 1918, negative in 1939, and positive in 1977. For the US the same author finds four breaks, occurring at 1905, 1926, 1942 and 1973. These breaks were then incorporated in the set-up of Robinson (1994) for testing the order of integration of the series.

Our fractional integration framework is appropriate for both stationary processes (implied by NAIRU models - see, e.g. Friedman, 1968, and Phelps, 1967), and highly persistent/nonstationary ones (as in hysteresis models - see, e.g., Blanchard and Summers, 1986, 1987, and Barro, 1988), and by incorporating structural breaks it can also be used to model processes exhibiting regime change (as in structuralist models - see, e.g., Phelps, 1994). It can therefore shed some light on the empirical relevance of alternative unemployment models with different policy implications. Note, however, that the value of $d$ by itself does not provide conclusive evidence in favour of any particular theory. For example, the NAIRU and the structuralist approach (with breaks) assume the existence of an equilibrium level to which the series converges, implicitly assuming that unemployment is mean-reverting $(\mathrm{d}<1)$. Persistence of unemployment under the hysteresis hypothesis, though, can also be consistent with values of $d$ smaller than though close to 1 , with the effect of the shocks disappearing in the very long run.

The results can be summarised as follows: if the underlying disturbances are white noise, the order of integration in both series is close to the unit root: 0.92 for the UK, and 1.02 for the US. However, if one allows for weak autocorrelation, the values are much smaller, around 0.10 for the UK and 0.18 for the US. These lower values, when AR disturbances are considered, may be explained by the competition between the AR 
parameters and the fractional differencing parameter in describing the degree of association between the observations. A crucial point is then to determine whether the series are autocorrelated or not. Several diagnostic tests carried out on the residual in the estimated models, along with Beran's (1992) goodness-of-fit statistic, suggest that UK unemployment can be described well as an I(d) process, with $d=0.09$ and AR(1) $u_{t}$. For the US, the order of integration seems to be slightly higher $(d=0.18)$, with an $\operatorname{AR}(2)$ structure for the disturbances. In conclusion, both series are stationary and mean-reverting, with the effects of the shocks dying away in the long run - even in the UK, for which it is generally thought that a hysteresis, rather than a NAIRU model is appropriate (unlike the US, where evidence for the latter is generally found). Our analysis points to a lower degree of persistence in the UK, suggesting that taking into account mean shifts provides stronger evidence that NAIRU models might be appropriate for both countries. Consequently, it appears that labour market reforms (more successful than previously thought even in the case of the UK) are the key to reducing unemployment. Further, the fact that the adjustment process is faster in the UK implies that more decisive policy actions are required in the US to bring unemployment back to its original level.

Another issue of interest is the dating of the breaks. For this purpose a procedure recently developed by Gil-Alana (2008) could be used; this enables one to determine the break dates endogenously in the context of fractional integration. A final issue is to establish whether the chosen model (based on fractional integration with multiple shifts) predicts better than other standard approaches based on integer 0/1 differentiation with or without structural breaks. This will be examined in future papers. 


\section{References}

Alogoskoufis, G.S. and Manning, A., 1988. On the persistence of unemployment. Econ. Policy, 7, 427-469.

Anderton, R., 1998. Policy regimes and the persistence of wage inflation and unemployment. Manch. Sch., 66, 418-438.

Bai, J. \& Perron, P. (1998). Estimation and testing linear models with multiple structural changes. Econometrica, 66, 47-78.

Barro, R., 1988. The natural rate theory reconsidered: the persistence of unemployment. Am. Econ. Rev., 78, 32-37.

Beran, J., (1992) A goodness of fit test for time series with long range dependence, Journal of the Royal Statistical Society B, 54, 749-760.

Bianchi, M. \& Zoega, G. (1997). Challenges facing natural rate theory. European Economic Review, 41, 535-547.

Blanchard, O. \& Summers, L. (1986). Hysteresis and the European unemployment problem. in S. Fischer ed. NBER Macroeconomics Annual, Cambridge, MA. MIT Press 15-78.

Blanchard, O.J. \& Summers, L.H. (1987). Hysteresis in unemployment. European Economic Review, 31, 288-295.

Blanchflower, D. and Freeman, R., 1994. Did the Thatcher reforms change British labour market performance?. in R. Barrell (ed.), The UK Labour Market, Cambridge, Cambridge University Press.

Cross, R., 1987. Hysteresis and instability in the natural rate of unemployment. Scand. J. Econ., 89(1), 71-89. 
Cross, R.B. (1994). The macroeconomic consequences of discontinuous adjustment: selected memory of non-dominated extrema. Scottish Journal of Political Economy, 41, 212221.

Cross, R.B. (1995). The Natural Rate of Unemployment: Reflections on 25 Years of the Hypothesis. Cambridge, UK, Cambridge University Press.

Dickey, D. A. \& Fuller, W.A. (1979). Distribution of the estimators for autoregressive time series with a unit root. Journal of the American Statistical Association, 74, 427-431.

Diebold, F.S. \& Inoue, A. (2001). Long memory and regime switching. Journal of Econometrics, 105, 131-159.

Diebold, F.X. \& Rudebusch, G.D. (1991). Is consumption too smooth? Long memory and the Deaton paradox. The Review of Economics and Statistics, 73, 1-9.

Elliot, G., T. Rothenberg \& Stock, J. (1996). Efficient tests for an autoregressive unit root, Econometrica, 64, 813-36.

Friedman, M., 1968. The role of monetary policy. Am. Econ. Rev., 58, 1-17.

Gil-Alana, L.A. (1999). Testing fractional integration with monthly data. Economic Modelling, 16, 613-629.

Gil-Alana, L.A. (2000). Mean reversion in the real exchange rates. Economics Letters, 69, $285-288$.

Gil-Alana, L.A. (2001). Testing stochastic cycles in macroeconomic time series. Journal of Time Series Analysis, 22, 411-430.

Gil-Alana, L.A., (2008), Fractional integration and structural breaks at unknown periods of time, Journal of Time Series Analysis 29, 163-185.

Gil-Alana, L.A. \& Robinson, P.M. (1997). Testing of unit roots and other nonstationary hypotheses in macroeconomic time series. Journal of Econometrics, 80, 241-268. 
Gil-Alana, L.A. \& Robinson, P.M. (2001). Testing seasonal fractional integration in the UK and Japanese consumption and income. Journal of Applied Econometrics, 16, 95-114.

Gourieroux, C. \& Jasiak, J. (2001). Memory and infrequent breaks. Economics Letters, 70, 29-41.

Granger, C.W.J. and N. Hyung (2004) Occasional structural breaks and long memory with an application to the S\&P 500 absolute stock returns. Journal of Empirical Finance 11, 399421.

Hassler, U. \& Wolters, J. (1994). On the power of unit root tests against fractional alternatives. Economics Letters, 45, 1-5.

Hegwood, N.D. (2004). A long run time series analysis of US and UK unemployment rates. forthcoming in the Proceedings of the Academy of Economics and Finance.

Kwiatkowski, D., Phillips, P.C.B., Schmidt, P. \& Shin, Y. (1992). Testing the null hypothesis of stationarity against the alternative of a unit root. Journal of Econometrics, 54, $159-178$.

Lee, D. and P. Schmidt, (1996), On the power of the KPSS test of stationarity against fractionally-integrated alternatives, Journal of Econometrics 73, 285-302.

Lindbeck, A. \& Snower, D.J. (1988). The Insider-Outsider Theory of Employment and Unemployment. Cambridge, Mass., MIT Press.

Mandelbrot, B., (1977), Fractals, form, chance and dimension, Freeman, San Francisco.

Ng, S. \& Perron, P. (2001). LAG Length Selection and the Construction of Unit Root Tests with Good Size and Power, Econometrica, 69 (6), 1519-54.

Phelps, E.S., 1994. Structural Slumps: The Modern Equilibrium Theory of Unemployment, Interest, and Assets, Cambridge, MA, Harvard University Press. 
Phillips, P.C.B. \& Perron, P. (1988). Testing for a unit root in a time series regression. Biometrika, 75, 335-346.

Robinson, P.M. (1994). Efficient tests of nonstationary hypotheses. Journal of the American Statistical Association, 89, 1420-1437.

Vogelsang, T.J. (1997). Wald-type tests for detecting breaks in the trend function of a dynamic time series. Econometric Theory, 13, 818-849. 


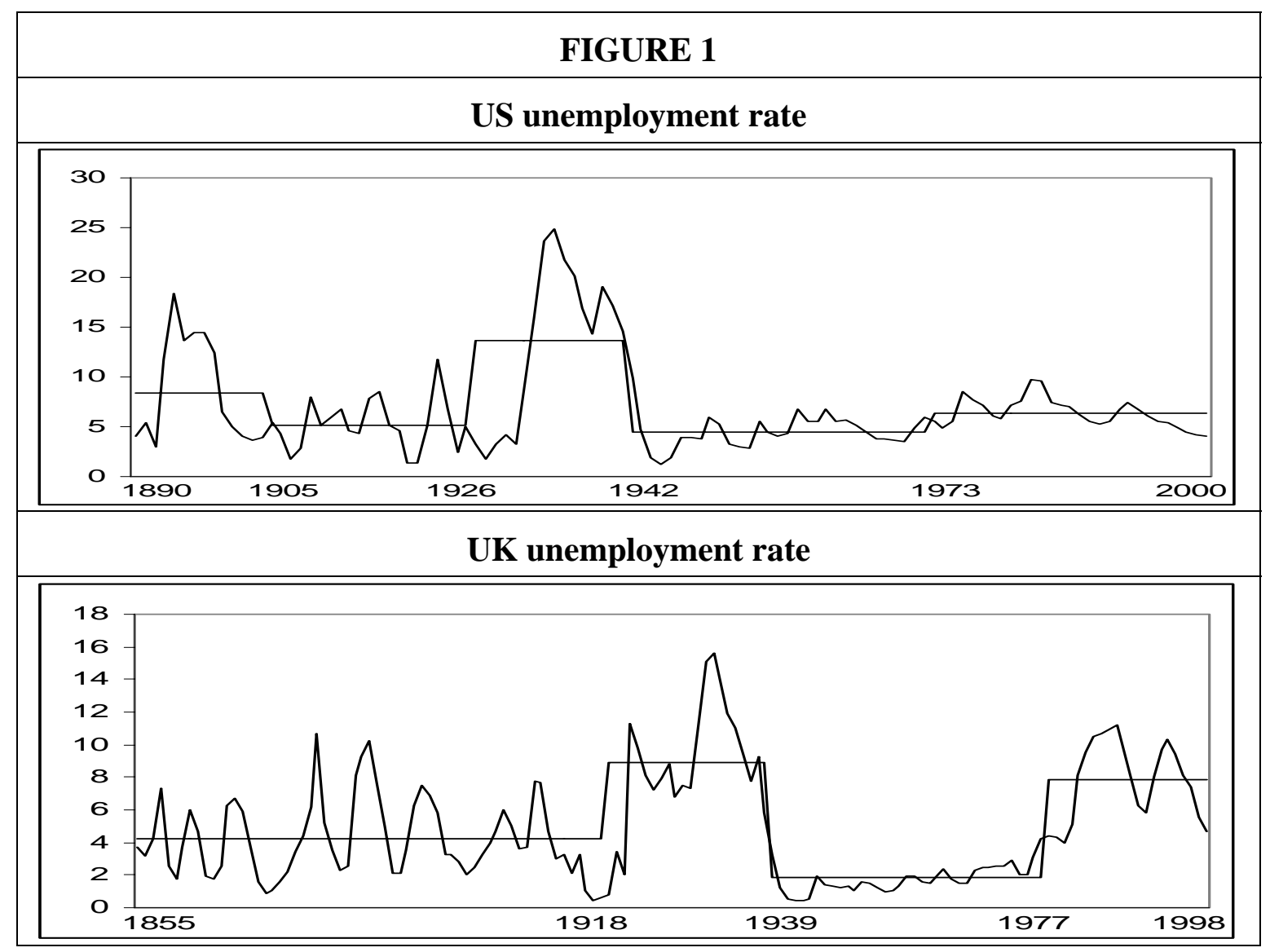


TABLE 1

\section{$95 \%$ confidence intervals of the non-rejection values of $d_{0}$}

\begin{tabular}{|c|c|c|}
\hline $\mathrm{U}_{\mathrm{t}} /$ Country & U.K. & U.S. \\
\hline White noise & {$\left[\begin{array}{lll}0.67 & (0.92) & 1.19\end{array}\right]$} & {$\left[\begin{array}{lll}0.79 & (1.02) & 1.30\end{array}\right]$} \\
\hline AR (1) & {$\left[\begin{array}{lll}0.00 & (0.09) & 0.22\end{array}\right]$} & {$\left[\begin{array}{lll}0.05 & (0.18) & 0.31\end{array}\right]$} \\
\hline AR (2) & {$\left[\begin{array}{lll}0.03 & (0.11) & 0.24\end{array}\right]$} & {$\left[\begin{array}{lll}0.02 & (0.18) & 0.33\end{array}\right]$} \\
\hline
\end{tabular}

\section{TABLE 2}

\section{Estimated values of the selected models in Table 1}

\begin{tabular}{|c|c|c|c|c|c|c|c|c|c|c|c|}
\hline Country & $\mathrm{u}_{\mathrm{t}}$ & $d_{o}^{*}$ & $\hat{r}$ & $\beta_{1}$ & $\beta_{2}$ & $\beta_{3}$ & $\beta_{4}$ & $\beta_{5}$ & $\Phi_{1}$ & $\Phi_{2}$ & Diagnostics \\
\hline \multirow{3}{*}{ UK } & W.N. & 0.92 & -0.0236 & 3.6351 & 4.0479 & 0.1938 & 0.5619 & --- & --- & --- & A \\
\hline & AR(1) & 0.09 & -0.0159 & -0.2729 & 3.8879 & -3.1981 & 2.3934 & --- & 0.628 & --- & $\mathrm{A}, \mathrm{B}, \mathrm{C}$ \\
\hline & $\mathrm{AR}(2)$ & 0.11 & -0.0273 & -0.1417 & 3.8538 & -3.2536 & 2.1930 & --- & 0.387 & 0.368 & $\mathrm{~A}$ \\
\hline \multirow{3}{*}{ US } & W.N. & 1.02 & -0.0165 & 3.9122 & 2.7868 & 1.3071 & -3.7752 & -4.5425 & --- & --- & A \\
\hline & $\mathrm{AR}(1)$ & 0.18 & -0.0195 & 3.5375 & -0.0875 & 6.6068 & -2.9345 & -3.7264 & 0.663 & --- & A \\
\hline & $\operatorname{AR}(2)$ & 0.18 & -0.0271 & 3.6325 & 0.0272 & 6.6010 & -2.9450 & -3.7353 & 0.789 & -0.199 & $\mathrm{~A}, \mathrm{~B}, \mathrm{C}$ \\
\hline
\end{tabular}

In bold the coefficients which are significant at the 5\% level; A stands for homoscedasticity and B for no serial correlation, whilst $\mathrm{C}$ for a functional form test. 


\begin{tabular}{|c|c|c|c|c|}
\hline \multicolumn{5}{|c|}{ TABLE 3 } \\
\hline \multicolumn{5}{|c|}{ Impulse response functions of the selected models } \\
\hline & \multicolumn{2}{|c|}{ U.K. } & \multicolumn{2}{c|}{ U.S } \\
\hline & W.N. & AR(1) & W.N. & AR(2) \\
\hline 0 & 1.000 & 1.000 & 1.000 & 1.000 \\
\hline 1 & .920 & .718 & 1.019 & .842 \\
\hline 2 & .883 & .499 & 1.030 & .665 \\
\hline 3 & .859 & .348 & 1.037 & .518 \\
\hline 4 & .842 & .245 & 1.042 & .404 \\
\hline 5 & .828 & .175 & 1.046 & .319 \\
\hline 6 & .817 & .128 & 1.049 & .256 \\
\hline 7 & .808 & .096 & 1.052 & .208 \\
\hline 8 & .800 & .074 & 1.055 & .173 \\
\hline 9 & .793 & .059 & 1.057 & .147 \\
\hline 10 & .787 & .049 & 1.060 & .126 \\
\hline 20 & .745 & .018 & 1.074 & .055 \\
\hline 30 & .722 & .012 & 1.082 & .037 \\
\hline 40 & .706 & .009 & 1.088 & .029 \\
\hline 50 & .693 & .007 & 1.093 & .024 \\
\hline
\end{tabular}

FIGURE 2

Impulse response functions for the UK and the US unemployment rates

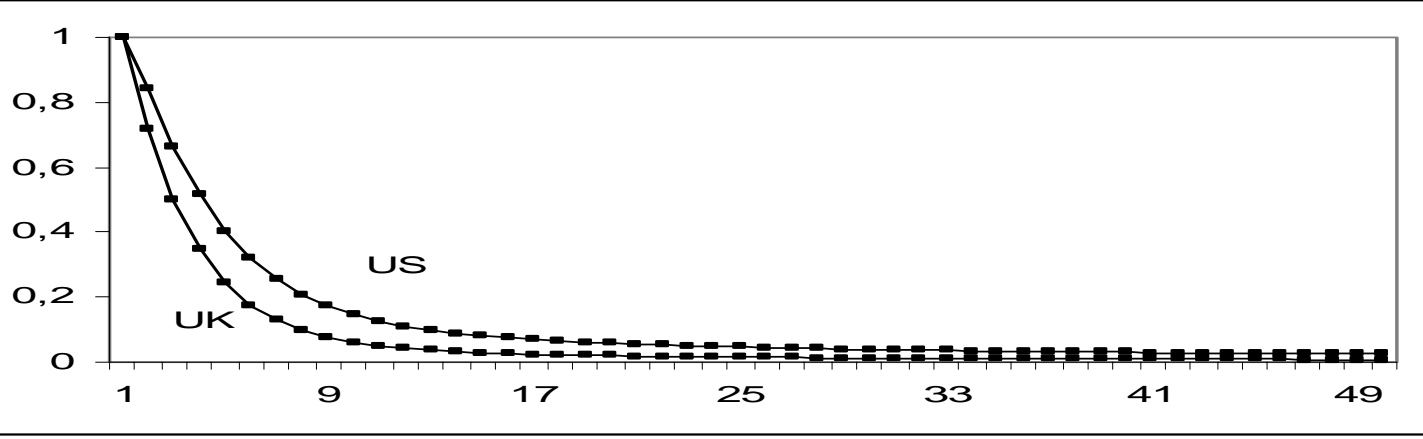


